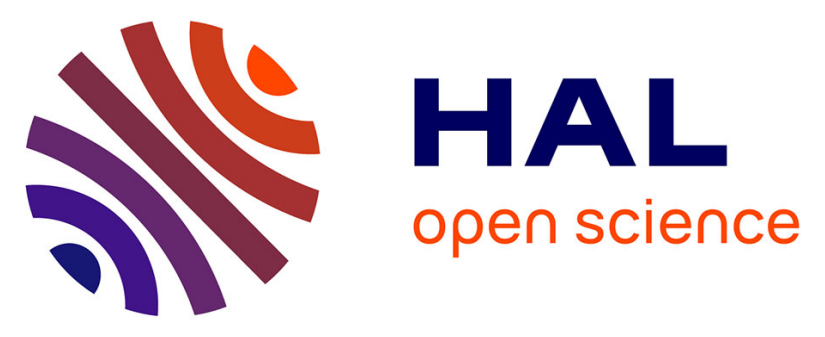

\title{
Polyethylene glycol crowding effect on hyaluronidase activity monitored by capillary electrophoresis
}

Rouba Nasreddine, Lucija Orlic, Ghassan Al Hamoui Dit Banni, Syntia Fayad, Axel Marchal, Francesco Piazza, Chrystel Lopin-Bon, Josef Hamacek, Reine Nehmé

\section{To cite this version:}

Rouba Nasreddine, Lucija Orlic, Ghassan Al Hamoui Dit Banni, Syntia Fayad, Axel Marchal, et al.. Polyethylene glycol crowding effect on hyaluronidase activity monitored by capillary electrophoresis. Analytical and Bioanalytical Chemistry, 2020, 412 (17), pp.4195-4207. 10.1007/s00216-020-02659-9 . hal-02939523

\section{HAL Id: hal-02939523 \\ https://hal.science/hal-02939523}

Submitted on 30 Jun 2021

HAL is a multi-disciplinary open access archive for the deposit and dissemination of scientific research documents, whether they are published or not. The documents may come from teaching and research institutions in France or abroad, or from public or private research centers.
L'archive ouverte pluridisciplinaire HAL, est destinée au dépôt et à la diffusion de documents scientifiques de niveau recherche, publiés ou non, émanant des établissements d'enseignement et de recherche français ou étrangers, des laboratoires publics ou privés.

\section{(ㄷ)(i)}

Distributed under a Creative Commons Attribution| 4.0 International License 


\title{
Polyethylene glycol crowding effect on hyaluronidase activity monitored by capillary electrophoresis
}

\author{
Rouba Nasreddine ${ }^{1} \cdot$ Lucija Orlic $^{1,2} \cdot$ Ghassan Al Hamoui Dit Banni $^{1} \cdot$ Syntia Fayad ${ }^{1,3}$ - Axel Marchal $^{3}$. \\ Francesco Piazza ${ }^{2} \cdot$ Chrystel Lopin-Bon $^{1} \cdot$ Josef Hamacek ${ }^{2} \cdot$ Reine Nehmé $^{1}$
}

\begin{abstract}
To mimic the activity of hyaluronidase in natural environment, the hydrolysis of hyaluronic acid (HA) by hyaluronidase was investigated for the first time in the presence of crowding agents using capillary electrophoresis (CE) as a simple and reliable technique for conducting enzymatic assay. Polyethylene glycol (PEG) 6000 was selected as a model crowder and the hyaluronic acid degradation catalyzed by bovine testes hyaluronidase (BTH) was carried out at different PEG concentrations $(0 \%, 10 \%$, and $17 \%)$. After optimization of the $\mathrm{CE}$ analytical method and enzymatic assay, the degradation products were monitored at different HA concentrations. At $10 \%$ of PEG and $0.3 \mathrm{mg} \mathrm{mL}^{-1}$ of $\mathrm{HA}$, the activity of the enzyme was significantly reduced showing inconvenient interactions of PEG with the hyaluronidase blocking the release of hydrolysis products. A similar reduction of hyaluronidase activity was observed at $1 \mathrm{mg} \mathrm{mL}^{-1}$ of HA due to the presumable formation of the BTH-substrate complex. The experimental curves obtained by $\mathrm{CE}$ also evidence that the overall kinetics are governed by the hydrolysis of hexasaccharide intermediates. Finally, the effect of PEG on hyaluronidase activity was evaluated in the presence of natural or synthetic inhibitors. Our results show a significant difference of the inhibitors' affinity toward hyaluronidase in the presence of PEG. Surprisingly, the presence of the crowding agent results in a loss of the inhibition effect of small polycyclic inhibitors, while larger charged inhibitors were less affected. In this work, CE analyses confirm the importance of mimicking the cellular environment for the discovery and development of reliable inhibitors.
\end{abstract}

Keywords Capillary electrophoresis $\cdot$ Crowding $\cdot$ Hyaluronidase activity $\cdot$ Inhibitors $\cdot$ Polysaccharide

\section{Abbreviations \\ BGE Background electrolyte \\ BTH Bovine testes hyaluronidase}

Rouba Nasreddine and Lucija Orlic contributed equally to this work.

Josef Hamacek

josef.hamacek@cnrs.fr

$\triangle$ Reine Nehmé

reine.nehme@univ-orleans.fr

1 Institut de Chimie Organique et Analytique (ICOA), CNRS FR 2708

- UMR 7311, Université d'Orléans, 45067 Orléans, France

2 Centre de Biophysique Moléculaire, CNRS UPR 4301, Université d'Orléans - CNRS, 45071 Orléans, France

3 Unité de recherche Enologie, USC 1366 INRA, Université de Bordeaux, ISVV, EA 5477, 33882 Villenave d'Ornon, France

$\begin{array}{ll}\text { CPA } & \text { Corrected peak area } \\ \text { CS-A } & \begin{array}{l}\text { Biotinylated 4-sulfated chondroitin } \\ \text { tetrasaccharides }\end{array} \\ \text { CS-C } & \begin{array}{l}\text { Biotinylated 6-sulfated chondroitin } \\ \text { tetrasaccharides }\end{array} \\ \text { Dec } & \text { Decasaccharide } \\ \text { Dod } & \text { Dodecasaccharide } \\ \text { ECM } & \text { Extracellular matrix } \\ \text { EGCG } & \text { Epigallocatechin gallate } \\ \text { HA } & \text { Hyaluronic acid } \\ \text { Hdec } & \text { Hexadecasaccharide } \\ \text { Hex } & \text { Hexasaccharide } \\ \text { IB } & \text { Incubation buffer } \\ \text { MC } & \text { Macromolecular crowding } \\ \text { Oct } & \text { Octasaccharide } \\ \text { QTT-I } & \text { Quercotriterpenoside-I } \\ \text { Tdec } & \text { Tetradecasaccharide } \\ \text { Tet } & \text { Tetrasaccharide } \\ \mu_{\text {eph }} & \text { Electrophoretic mobility } \\ \text { DIM } & \text { Dimeric }\end{array}$




\section{Introduction}

Historically, enzymatic studies were assayed in vitro, in dilute conditions, without considering the complexity of real in vivo conditions such as the cellular environment. A wide variety of biomolecules (proteins, nucleic acids, ribosomes, and carbohydrates) occupy $20-40 \%$ of the total volume of a typical cell [1-3]. The activity of an enzyme in such crowded media can be very different in comparison to dilute conditions [3-5]. This may be evaluated experimentally by using concentrated solutions of model "crowding agents" such as polyethylene glycol (PEG), dextran, Ficoll (branched carbohydrate derivative), or inert proteins [5]. Most of the enzymatic studies carried out in vitro under macromolecular crowding (MC) conditions have been monitored either by UV-visible spectroscopy, fluorescence, or far UV-circular dichroism spectroscopy [6-9]. Some other studies have used isothermal titration calorimetry and turbidimetric methods to study the effect of crowders on enzymatic activity $[10,11]$.

Capillary electrophoresis (CE) is a well-established separative technique that enables fast, highly efficient, cost-effective analyses of a wide range of molecules [12]. Several detection tools may be used in conjugation/hyphenation with CE such as UV, fluorescence, contactless conductivity, and mass spectrometry [13-20]. CE offers the possibility to carry out enzymatic assays using two main homogeneous approaches, in which neither the enzyme nor the substrate is immobilized: (i) off-line or pre-capillary mode and (ii) on-line or in-capillary mode. For the off-line assays, the enzymatic reaction is performed in a vial, before the introduction of the reaction mixture into the capillary. The on-line mode implies that the reaction takes place directly inside the capillary that plays the role of an enzymatic nanoreactor [14, 21]. In this work, we study for the first time the effect of crowding media on hyaluronidase activity using two techniques, a referenced one based on neocuproine spectrophotometry [22] and a pre-capillary CEUV-based assay previously developed by our laboratory [17]. The hyaluronic acid (HA) or hyaluronan is a major component of the extracellular matrix (ECM) and is especially abundant in loose connective tissue [23-25]. It is a linear polysaccharide that forms long, worm-like filaments in aqueous solutions allowing to hold/trap approximately 1000 times its weight of water giving tissues such as the skin its viscoelasticity, hydrophilicity [6, 26], and plasticity [27]. HA is increasingly used as a non-immunogenic and a non-inflammatory filler and scaffolding material in cosmetic dermatology [6]. It is a nonsulfated glycosaminoglycan with repeating disaccharide units of D-glucuronic acid $(\beta 1 \rightarrow 3)$ and $N$-acetyl-D-glucosamine $(\beta 1 \rightarrow 4)$. The size and abundance of HA are controlled by hyaluronidases. Bovine testicular hyaluronidase (BTH) and all human hyaluronidases specifically split the $\beta 1,4$ glucosaminidic bond between $\mathrm{C} 1$ of the glucosamine moiety and $\mathrm{C} 4$ of the glucuronic acid [28]. This produces oligosaccharides of an even number of repeating monosaccharide units (n). The tetrasaccharide (Tet, $n=4$ ) is considered as the final product of the BTH hydrolysis reaction $[24,29]$. The products of HA degradation are implicated in different pathological processes including inflammation, tumor progression [30,31], epidermal homeostasis, and skin aging [25]. For this, searching for inhibitors of hyaluronidase is of great interest $[28,31]$.

BTH activity is conventionally monitored by spectrophotometry and viscosimetry methods [22, 32]. These techniques are prone to interferences and only allow the determination of the total hyaluronidase activity and not the quantification of the different oligomeric species. In order to quantify precisely the obtained products of BTH degradation, HPLC and size exclusion chromatography with UV and/or mass spectrometry detection have been explored [4, 33-36]. CE-UV was also used to obtain a complete identification of the HA degradation products after electrophoretic separation and quantitative detection $[17,19,21,37-40]$.

This study was focused on the evaluation of the effect of a typical crowding agent, namely PEG 6000, on HA degradation by BTH. The activity of hyaluronidase was monitored by following the concentration of oligomer products during kinetic runs at different concentrations of the crowding agent. Several optimizations were performed concerning the injection conditions and reaction time for CE-UV. The optimized conditions were then applied to follow the reaction in different enzymatic media with CE-UV and the neocuproine assay in parallel. Since CE separation provides information on free concentrations of reaction intermediates and final products, a better insight into the mechanism of HA degradation at different crowding conditions has been obtained. Finally, natural inhibitors, epigallocatechin gallate (EGCG) and quercotriterpenoside-I (QTT-I), as well as two original synthesized inhibitors were tested in order to evaluate their effect on hyaluronidase activity in the presence of PEG 6000.

\section{Experimental}

\section{Materials and methods}

\section{Chemicals}

All reagents were of analytical grade and used as received without any further purification. Ammonium acetate $\left(\mathrm{CH}_{3} \mathrm{COONH}_{4}\right.$, purity $\left.\geq 98 \%\right)$, epigallocatechin gallate (EGCG, purity $\geq 95 \%$ ), hyaluronidase type I-S from bovine testes (BTH, 400-1000 units $\mathrm{mg}^{-1}$ solid, CAS 37326-33-3, sodium acetate $\left(\mathrm{CH}_{3} \mathrm{COONa}\right.$, purity $\left.\geq 99 \%\right)$, sodium hydroxide $(\mathrm{NaOH}$, purity $\geq 98 \%$ ), and oligohyaluronic acid (oligoHA4 or tetrasaccharide (Tet), $\mathrm{C}_{28} \mathrm{H}_{44} \mathrm{~N}_{2} \mathrm{O}_{23}$ ) were purchased from Sigma-Aldrich (Saint-Quentin Fallavier, France). 
Hyaluronic acid, sodium salt, and Streptococcus pyrogenes (HA, CAS 9067-32-7 - Calbiochem) were purchased from Merck Millipore (Molsheim, France). Glacial acetic acid $\left(\mathrm{CH}_{3} \mathrm{COOH}\right)$ and ammonia $\left(\mathrm{NH}_{4} \mathrm{OH}, 28 \%\right)$ were purchased from VWR International (Fontenay-sous-Bois, France).

Biotinylated 4-sulfated (CS-A) and 6-sulfated (CS-C) chondroitin tetrasaccharides, two original synthetic oligosaccharides, were synthesized in our laboratory [41] and tested as inhibitors of hyaluronidase activity.

Polyethylene glycol (PEG) 6000 was purchased from Merck, USA. Hydrochloric acid $(\mathrm{HCl})$ was purchased from Fisher (Thermo Fisher Scientific Corp., USA). Potassium carbonate (Aldrich, USA), glycine (Aldrich, USA), cupric sulfate pentahydrate (Merck, USA), and 2,9-dimethyl-1,10phenanthroline hemihydrate (neocuproine) were purchased from Alfa Aesar (Thermo Fisher Scientific Corp., USA).

Quercotriterpenoside-I (QTT-I) or 23-O-galloyl arjungenin 28-O- $\beta$-glucopyranosyl with the molecular formula $\mathrm{C}_{43} \mathrm{H}_{62} \mathrm{O}_{15}$ was isolated from an extract of Quercus petraea wood using centrifugal partition chromatography fractionation and high-performance liquid chromatography purification according to the procedure described by Marchal and coworkers [42].

Ultrapure water $(18.2 \mathrm{M} \Omega-\mathrm{cm})$ was produced from an Elga apparatus (Elga, Villeurbanne, France). Syringes and hydrophilic polyvinylidenedifluoride (PVDF) Econo Syringe Filters, pore size $0.2 \mu \mathrm{m}$, were purchased from Agilent, USA.

\section{Solutions}

All buffer solutions, with and without crowders, were freshly prepared every day in ultrapure water. Then, their $\mathrm{pH}$ was adjusted before being filtered and stored at $4{ }^{\circ} \mathrm{C}$.

Buffers The incubation buffer (IB) was prepared by dissolving the appropriate amount of sodium acetate in ultrapure water to make a $2 \mathrm{mM}$ solution and the $\mathrm{pH}$ was adjusted to 4.3 with $1 \mathrm{M}$ glacial acetic acid. The background electrolyte (BGE) for capillary electrophoresis was prepared by dissolving the appropriate amount of ammonium acetate in ultrapure water to make a $50 \mathrm{mM}$ solution. The $\mathrm{pH}$ was adjusted to 8.9 with $1 \mathrm{M}$ ammonia.

Stock solutions Stock solutions of BTH, HA, EGCG, and tetrasaccharide were prepared in the IB at a concentration of $10 \mathrm{mg} \mathrm{mL}^{-1}$ and diluted to the appropriate concentrations in the same buffer. The enzyme stock solution was prepared at $10 \mathrm{mg} \mathrm{mL}^{-1}$ and then aliquots of $2 \mathrm{mg} \mathrm{mL}^{-1}$ were stored at $20^{\circ} \mathrm{C}$. Stock solutions of CS-A and CS-C were prepared at $10 \mathrm{mg} \mathrm{mL}^{-1}$ in ultrapure water and then diluted in the IB to the appropriate concentration. QTT-I stock solutions were prepared at $40 \mathrm{mg} \mathrm{mL}^{-1}$ in pure methanol and then diluted in ultrapure water to the appropriate concentration.
Stock solutions of PEG 6000 were prepared by dissolving the appropriate amount in the IB to have $7 \%$, $14 \%$, and $25 \%(\mathrm{w} / \mathrm{w})$ solutions in order to have a final concentration in the reaction media equal to $5 \%, 10 \%$, and $17 \%$, respectively. The $\mathrm{pH}$ of this mixture was adjusted to 4.3 with $1 \mathrm{M}$ or $5 \mathrm{M}$ of glacial acetic acid. The solutions were then homogenized with the homogenizer 850 (Fisher Scientific, USA) seven times for $3 \mathrm{~min}$ at $11,000 \mathrm{rpm}$, with $1 \mathrm{~min}$ between cycles to prevent overheating as optimized in our previous work [9]. This step helps preventing the formation of aggregates but no breakdown of PEG was observed as shown by dynamic light scattering. The dimensions of the homogenizer probe were $7 \mathrm{~mm} \times 115 \mathrm{~mm}$. Finally, the solutions were filtered through 0.2 CHROMAFIL Xtra regenerated cellulose syringe filters (Macherey-Nagel, Germany) and stored at $-20{ }^{\circ} \mathrm{C}$ before use.

\section{Instrumentation and operating conditions}

\section{Neocuproine spectrophotometric assay}

The assay was performed as described in the work of Vercruysse et al. [22] with the exception of using potassium carbonate instead of sodium carbonate. Briefly, two reagents, named C and D in the work of Vercruysse, were prepared as follows: $19.5 \mathrm{mg}$ of neocuproine was dissolved in $10 \mathrm{~mL}$ of ultrapure water followed by adding $1 \mathrm{M} \mathrm{HCl}$ until neocuproine is dissolved (reagent $\mathrm{C}$ ). To prepare reagent $\mathrm{D}$, $521 \mathrm{mg}$ of potassium carbonate, $160 \mathrm{mg}$ of glycine, and $4.5 \mathrm{mg}$ of cupric sulfate pentahydrate were dissolved in $10 \mathrm{~mL}$ of ultrapure water. Both reagents were stored at $4{ }^{\circ} \mathrm{C}$.

In this assay, $\mathrm{Cu}^{2+}$ is reduced to $\mathrm{Cu}^{+}$that binds to neocuproine resulting in the shift of the absorption spectrum of this compound. Reagent and sample volumes were optimized in this study. Forty microliters of reagent $\mathrm{C}$ and $40 \mu \mathrm{L}$ of reagent $\mathrm{D}$ were added to $20 \mu \mathrm{L}$ of the reaction mixture. After $12 \mathrm{~min}$ of incubation at $100{ }^{\circ} \mathrm{C}$ and cooling down, $100-200 \mu \mathrm{L}$ of water was added to the assay mixture. Then, $200 \mu \mathrm{L}$ of the mixture was pipetted on a 96-well plate. The absorbance at $450 \mathrm{~nm}$ was measured with a Mithras plate reader (Berthold, Germany).

\section{Capillary electrophoresis analysis}

All enzymatic reactions were conducted by off-line assays based on the protocol previously developed by our laboratory $[17,37,40]$. Bovine testes hyaluronidase (BTH) was chosen since it is commercially available and presents a similar activity to that of the human hyaluronidase [43].

For all the reactions, unless otherwise stated, $35 \mu \mathrm{L}$ of incubation buffer or PEG solution was pre-incubated with an appropriate volume of HA $\left(10 \mathrm{mg} \mathrm{mL}^{-1}\right)$ for 
$10 \mathrm{~min}$ at $37^{\circ} \mathrm{C}$ and then $5 \mu \mathrm{L}$ of enzyme solution was added to the reaction mixture, so that the final concentration of the enzyme in the mixture was $0.2 \mathrm{mg} \mathrm{mL}^{-1}$. Reactions were incubated at $37{ }^{\circ} \mathrm{C}$ for $180 \mathrm{~min}$ and then stopped by increasing the temperature using a water bath to $90{ }^{\circ} \mathrm{C}$ for $10 \mathrm{~min}$. For the inhibition assay, the reactions were carried out and stopped using the same protocol described above. More precisely, $25 \mu \mathrm{L}$ of IB or PEG solution was pre-incubated with $10 \mu \mathrm{L}$ of HA and $10 \mu \mathrm{L}$ of inhibitor before adding $5 \mu \mathrm{L}$ of enzyme. All reactions were carried out in duplicate.

The reaction mixtures were analyzed on a Beckman P/ACE MDQ (AB Sciex, USA) CE apparatus equipped with a photodiode array detector. The control of CE was performed using the Beckman 32 karat software (Beckman Coulter, USA). Uncoated fused silica capillaries purchased from Polymicro Technologies (Phoenix, AZ, USA) were used. The total length of the capillary was $57 \mathrm{~cm}$ (47 cm to the detector) with 50- $\mu \mathrm{m}$ inner diameter. The detection wavelength was set at $200 \mathrm{~nm}$ (bandwidth $10 \mathrm{~nm}$ ). New capillaries were conditioned by performing the following rinsing cycles: $1 \mathrm{M} \mathrm{NaOH}$ (10 min), water (10 min), and BGE (10 $\mathrm{min})$. At the start of each working day, the capillary was rinsed with $1 \mathrm{M} \mathrm{NaOH}$ (5 min), water (5 min), and BGE (5 min), followed by applying $+15 \mathrm{kV}$ (10 min) [44]. Between the runs, the capillary was flushed with $\mathrm{NaOH}$ (5 min), water $(0.5 \mathrm{~min})$, and $\mathrm{BGE}(3 \mathrm{~min})$ to ensure a good cleaning of the inner capillary surface. At the end of each day, the capillary was rinsed with $\mathrm{NaOH}(10 \mathrm{~min})$ and water $(10 \mathrm{~min})$, both at $50 \mathrm{psi}$ and stored overnight in water at $25{ }^{\circ} \mathrm{C}$. All rinse cycles were carried out at 30 psi.

Electrokinetic and hydrodynamic injections were performed from the anodic side of the capillary. The electrokinetic injections were tested at different voltages. On the other hand, the hydrodynamic injection conditions were optimized to achieve consistency and comparability. For both types of injection, the separation was performed in normal polarity mode at $+15-\mathrm{kV}$ separation voltage. The corrected peak area (CPA), which is the ratio of area over the migration time, was used as a reliable mean for the quantification of different electropherogram peaks. It is assumed that the absorbance measured at $200 \mathrm{~nm}$ is proportional to the number of dimeric motifs within the HA oligomer.

For inhibition assays, all inhibitors were tested at $1 \mathrm{mg} / \mathrm{mL}$ : (i) EGCG, a well-known inhibitor of hyaluronidase [37]; (ii) CS-A and CS-C, original synthesized inhibitors previously assayed for their hyaluronidase inhibition using CE by our laboratory [40]; and (iii) quercotriterpenoside-I (QTT-I), a natural compound we isolated from an oak wood extract [42]. For all tested inhibitors, the percentage of inhibition was calculated according to Eq. 1.

$\% I=\left(1-\frac{A_{x}}{A_{0}}\right) \times 100$

where $A_{x}$ is the CPA of the tetrasaccharide product formed in the presence of the inhibitor and $A_{0}$ is the CPA of the tetrasaccharide product formed in the absence of an inhibitor.

\section{Results and discussion}

Hyaluronidase activity was investigated in the absence and in the presence of PEG 6000 using the conventional neocuproine spectrophotometry technique as well as capillary electrophoresis (CE). The neocuproine assay enables the determination of the total amount of reducing ends of HA hydrolysis by measuring absorbance at $450 \mathrm{~nm}$. CE allows the separation and the quantitative detection of different products obtained after the HA hydrolysis leading to a better understanding of BTH activity in a crowded environment and in the presence of inhibitors.

\section{Capillary electrophoresis-based enzymatic assays}

CE-UV was used to investigate the influence of PEG 6000 on HA hydrolysis. Tests were conducted at different concentrations of crowders, between 5 and $30 \%$. The activity of hyaluronidase was determined by following the formation of the tetrasaccharide (Tet) fraction (oligo-HA4) which is the final product of HA hydrolysis by hyaluronidase. Our previously developed precapillary CE assay was adapted and used for this study [17]. Firstly, the influence of PEG 6000 on the repeatability of the injections into the capillary and on the electrophoretic separation of the obtained products was evaluated. Secondly, the hyaluronidase activity was monitored in the presence of the crowder.

\section{Optimization of injection}

The addition of PEG 6000 to the reaction media will inevitably increase its viscosity [45] which will result in inaccurate and unreproducible injections of representative samples into the capillary [13]. Consequently, being known to be well adapted for viscous samples [44], electrokinetic injection was tested by applying 5, 10, and $15 \mathrm{kV}$ (positive and negative polarities) for $5 \mathrm{~s}$. Hydrodynamic injection was also employed and optimized by applying a pressure of 0.5 psi or 1.5 psi for $5 \mathrm{~s}$ (respectively corresponding to $5 \mathrm{~nL}$ and $15 \mathrm{~nL}$ when using dilute solutions with a viscosity comparable to water according to Poiseuille equation). The hyaluronidase activity was assessed in the absence of PEG and in its presence at 10 and $17 \%$. Working with higher concentrations of PEG (25\% and 30\%) was excluded 
because the high viscosity of the solutions prevented an accurate preparation of the incubation media (pipetting issues for example). The influence of the crowders on the injection quality was evaluated at different concentrations of HA between 0.1 and $1.2 \mathrm{mg} \mathrm{mL}^{-1}$. Other conditions were similar to those presented above. The CPA value of the tetrasaccharide product peak was monitored in the different conditions.

Using the electrokinetic injection, the detected peaks were of low intensity and poor CPA repeatability even in the absence of the crowding agent. These results indicate that this approach is not suitable for the injection of the hyaluronidase reaction mixture. Indeed, it is known that the electrokinetic injection is less suitable for anions since it depends on the magnitude of the electrophoretic mobilities compared with the electroosmotic flow (EOF). When performing hydrodynamic injections at $0.5 \mathrm{psi}$ for $5 \mathrm{~s}$, results were not repeatable in the presence of PEG $17 \%$. Using 1.5 psi for $5 \mathrm{~s}$ ensured good repeatability of the CPA of the tetrasaccharide peak for the different substrate concentrations. However, when the HA concentration was higher than $0.5 \mathrm{mg} \mathrm{mL}^{-1}$, the CPA values decreased in the presence of PEG at $17 \%$. This is due to the high viscosity of the injected reaction media engendered by the presence of both polymers, PEG and the HA at high concentrations.

Based on these results, the hydrodynamic injection was fixed at $1.5 \mathrm{psi}$ for $5 \mathrm{~s}$ for the rest of the study.

\section{Influence of PEG on the electrophoretic separation of reaction products}

The electropherograms recorded in the presence of PEG 6000 show that the overall separation is not affected by the presence of PEG regardless of its concentration (Fig. 1). Nevertheless, the peaks are wider and less intense, and the analysis time increases with the increase of PEG concentration. More precisely, the EOF decreased from $4.38 \times 10^{-4} \mathrm{~cm}^{2} \mathrm{~V}^{-1} \mathrm{~s}^{-1}$ at $0 \%$ of PEG to $4.08 \times 10^{-4} \mathrm{~cm}^{2} \mathrm{~V}^{-1} \mathrm{~s}^{-1}$ at $10 \%$ PEG to reach $3.82 \times 10^{-4} \mathrm{~cm}^{2} \mathrm{~V}^{-1} \mathrm{~s}^{-1}$ at $17 \%$ PEG. This corresponds to a decrease of the electroosmotic flow of $6.8 \%$ and $12.8 \%$ in the presence of $10 \%$ and $17 \%$ PEG, respectively. This decrease of $\mu_{\text {eof }}$ may be associated to the relatively high viscosities of the analyzed samples and a possible non-covalent neutral coating of the inner capillary wall formed by hydrogen interactions between PEG and the silanol groups. However, this coating is known to be unstable when using an alkaline BGE, such as pH 8.9 in this study [44, 46, 47]. On the other hand, the migration time of the substrate HA also increases in the presence of PEG. The electrophoretic mobilities of HA $\left(\mu_{\mathrm{eph}}\right)$ in the absence of PEG was $2.16 \times 10^{-4} \mathrm{~cm}^{2} \mathrm{~V}^{-1} \mathrm{~s}^{-1}$. Adding $10 \%$ PEG had a negligible effect on $\mu_{\text {eph }}(2.13 \times$ $10^{-4} \mathrm{~cm}^{2} \mathrm{~V}^{-1} \mathrm{~s}^{-1}$ ) while adding $17 \%$ PEG caused a decrease of $6.9 \%$ of the $\mu_{\text {eph }}\left(2.01 \times 10^{-4} \mathrm{~cm}^{2} \mathrm{~V}^{-1} \mathrm{~s}^{-1}\right)$. These results suggest that HA interacts with higher concentrations of PEG, which changes the charge-to-size ratio of HA and hence its apparent mobility.

\section{Enzymatic assays in the presence of PEG}

A series of enzymatic assays were conducted at standard conditions and in the presence of PEG 6000, at $10 \%$ and $17 \%$. The separation of hydrolysis products at different concentrations of HA between 0.1 and $1.0 \mathrm{mg} \mathrm{mL}^{-1}$ was carried out by CE-UV. Assays were conducted using the previously

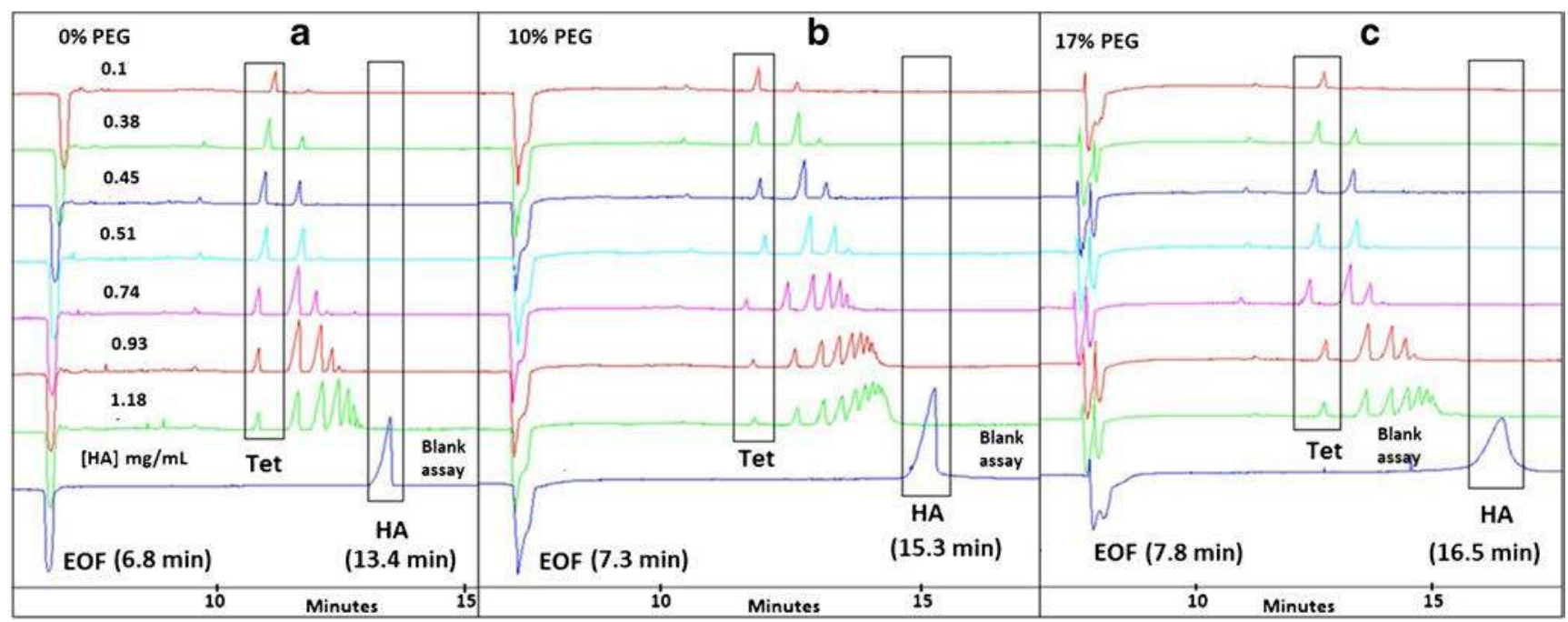

Fig. 1 Electropherograms of HA hydrolysis by hyaluronidase at different concentrations of HA at $0 \%$ PEG (a), 10\% PEG (b), and 17\% PEG (c). Reaction mixture in IB: $0.2 \mathrm{mg} \mathrm{mL}^{-1}$ hyaluronidase and HA $(0.1$ to $1.18 \mathrm{mg} \mathrm{mL}{ }^{-1}$ ). Incubation at $37^{\circ} \mathrm{C}$ for $180 \mathrm{~min}$. IB: $2 \mathrm{mM}$ sodium acetate $(\mathrm{pH} 4.3)$. Blank assay conducted in the absence of hyaluronidase in the reaction mixture. Electrophoretic separation conditions: BGE: $50 \mathrm{mM}$ ammonium acetate $(\mathrm{pH} 8.9)$; anodic injection: 1.5 psi for $5 \mathrm{~s}$; separation: $+15 \mathrm{kV}$ at $25^{\circ} \mathrm{C}$; detection: $\lambda=200 \mathrm{~nm}$; rinse between analyses at 30 psi: $5 \mathrm{~min} \mathrm{NaOH}(1 \mathrm{M}), 0.5 \mathrm{~min}$ water, and $3 \mathrm{~min}$ BGE; bare-silica capillary: $57 \mathrm{~cm}$ total length, $47 \mathrm{~cm}$ detection length, $50 \mu \mathrm{m}$ i.d. Peak identification: electroosmotic flow (EOF) and tetrasaccharide (Tet) 

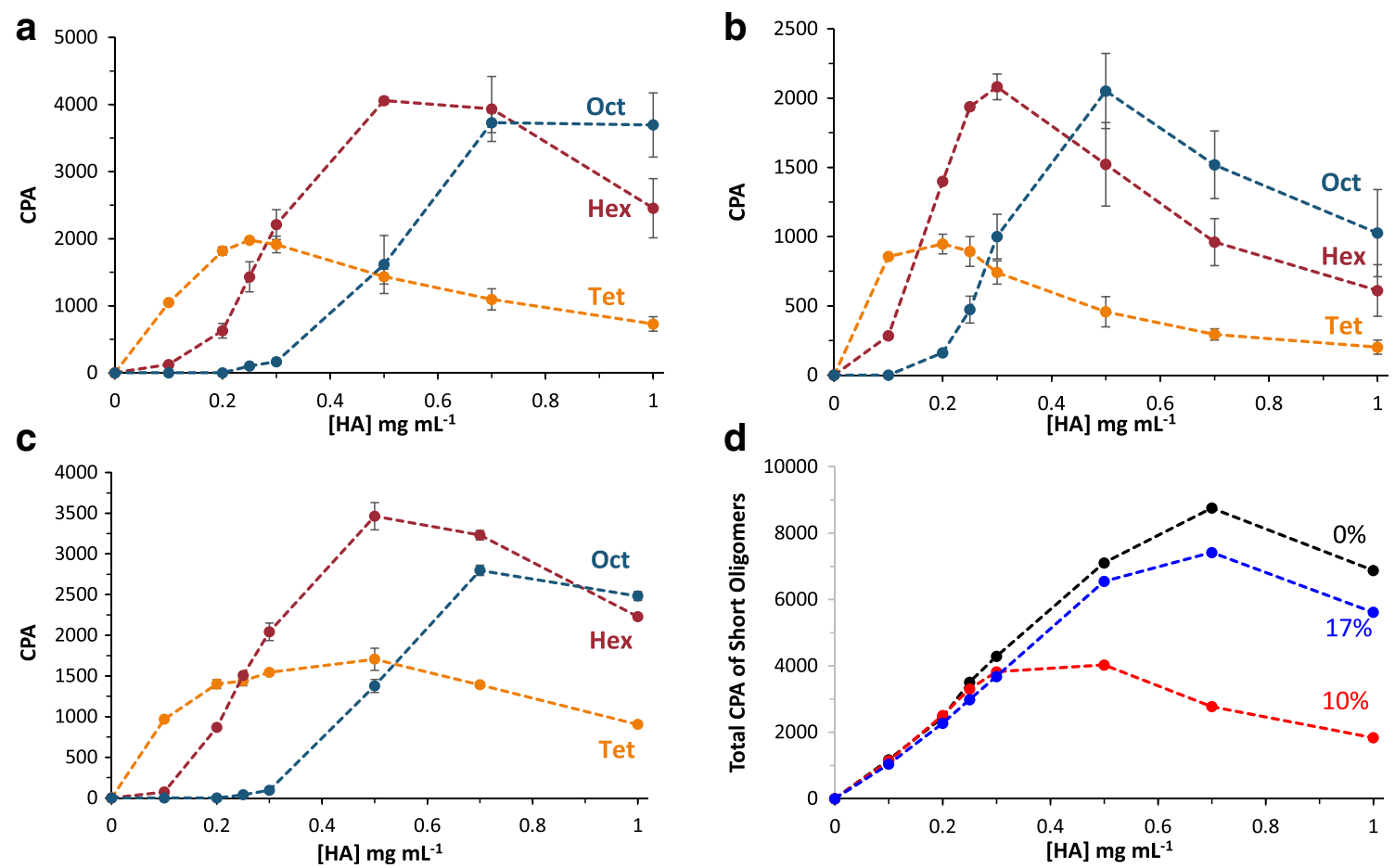

Fig. 2 Corrected peak area (CPA) values obtained by CE for tetrasaccharide (Tet), hexasaccharide (Hex), and octasaccharide (Oct) to monitor the influence of different concentrations of PEG 6000 on hyaluronidase activity: $0 \%$ (a), $10 \%$ (b), and 17\% (c). The total CPAs of short

optimized conditions (incubation time of $180 \mathrm{~min}$ at $37^{\circ} \mathrm{C}$ ). The quantity of the three main products obtained by HA hydrolysis, viz. Tet, hexasaccharide (Hex, $n=6)$, and octasaccharide (Oct, $n=8$ ), was evaluated by monitoring their CPAs. The CPA of dimeric (Dim) species during these analyses was zero or negligible to be analyzed here. The relative evolution of species concentrations in the absence of PEG (Fig. 2a) shows that Tet, a hydrolysis product that cannot be hydrolyzed further, is the major species at low HA concentrations, since higher oligomers have been already degraded. The evolution of CPA of Tet indicates that the hydrolysis rate increases up to $\sim 0.3 \mathrm{mg} \mathrm{mL}^{-1}$ of HA and significantly decreases for higher substrate concentrations whereas Hex and Oct intermediates are still detected in the solution. This observation can be related to the inhibition of BTH at high substrate concentrations, presumably due to the formation of an electrostatic BTH-HA complex. Indeed, Lenormand et al. [48] have shown that the main reason of a reduced BTH activity when the substrate concentration increases was the formation of an inactive form of BTH due to its complexation with the HA. To confirm this observation, the authors have used BSA (bovine serum albumin) to complex the HA. The formation of the novel HA-BSA complex liberates the enzyme as observed by a resurgence of its activity. Moreover, the increasing viscosity at high $\mathrm{HA}$ concentration of $1 \mathrm{mg} \mathrm{mL}^{-1}$ would be suspected to diminish the available water (binding water). Water plays a major role in the hydrolytic event since the

oligosaccharides obtained as the sum of CPAs for Tet, Hex, and Oct species detected and quantified during a single $\mathrm{CE}$ run are presented in (d). Incubation time: $180 \mathrm{~min}$. Other conditions: Fig. 1. The dashed lines in the figures are guide for the eye

enzymatic breakdown of HA involves both HA and water. However, a very recent study [49] showed using nearinfrared (NIR) spectroscopy that HA actively interacts with water and the difference in interaction with water at 0.1 and $1 \mathrm{mg} \mathrm{mL}^{-1}$ of HA was not significant.

The addition of PEG 6000 into the reaction mixture globally slows down the HA degradation as shown by the levels of short oligomers in Fig. $2 \mathrm{~b}$ and c, especially in the presence of $10 \%$ PEG. While the HA is almost completely hydrolyzed for total concentrations below $\sim 0.3 \mathrm{mg} \mathrm{mL}^{-1}$ independent of crowder concentration, the total amount of shorter oligomers decreases at higher concentrations of HA in a similar fashion for the three PEG concentrations (Fig. 2d), although the system with $10 \%$ PEG is more affected than the one with $17 \%$. This global evolution presumably points out to the combination of (i) the inhibition by excess HA described above and (ii) non-specific interactions of the enzyme with PEG hindering its activity and/or the diminution of the enzyme/substrate diffusion coefficient in the crowded reaction media. The increase of the total viscosity was described by Han and coworkers and reviewed by Mittal and coworkers [45, 50]. The partial recovery of BTH activity at higher HA concentrations and 17\% PEG may possibly occur due to an increase of the effective enzyme concentration, when the enzyme is released from the BTH-HA complex being in competition with PEG, or by the excluded volume effect [48]. 

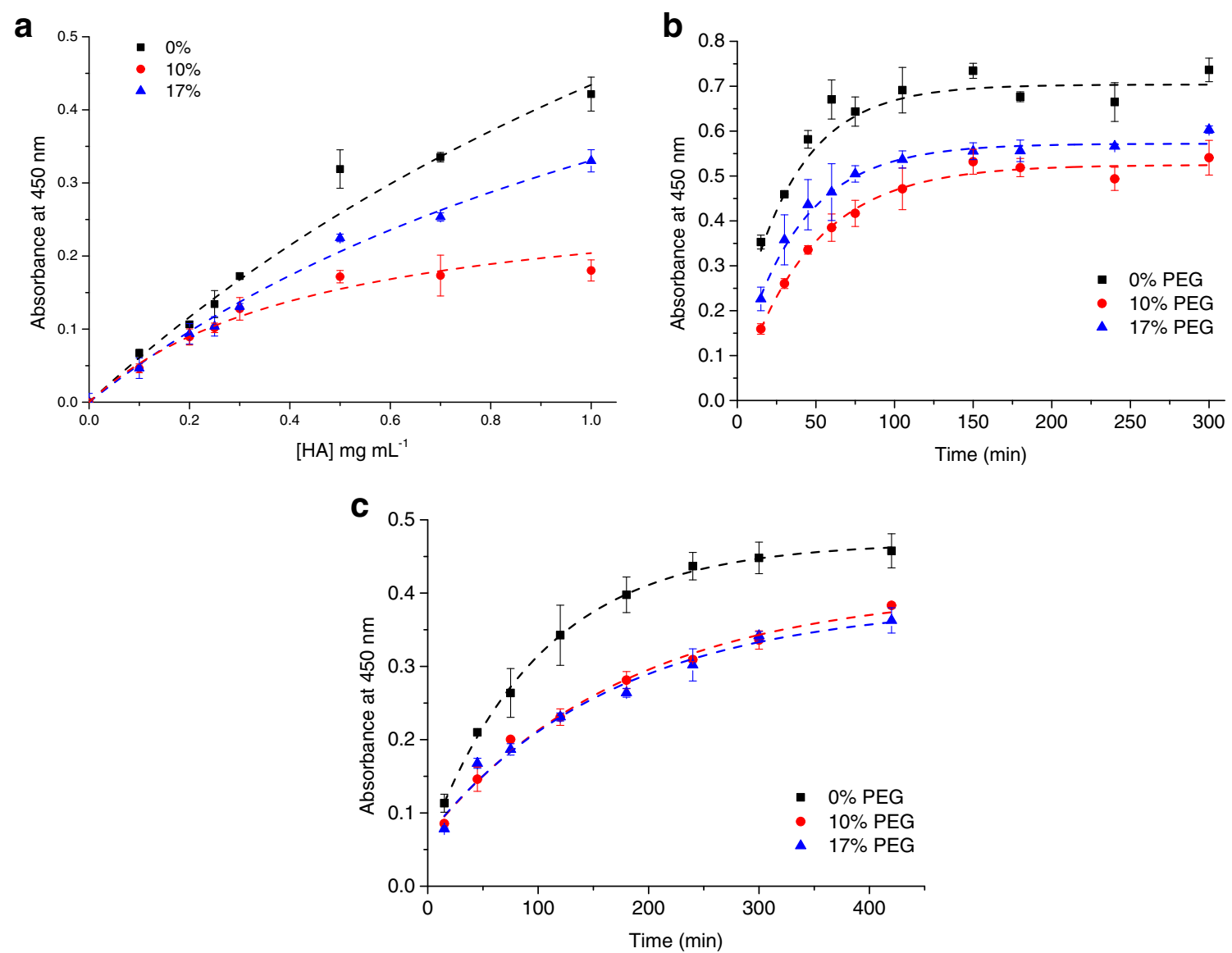

Fig. 3 Neocuproine spectrophotometric assay of the hydrolysis of HA by hyaluronidase at different concentrations of HA incubated for $180 \mathrm{~min}$ (the trends correspond to hyperbolas supposing Michaelis-Menten kinetics) (a); the evolution of total absorbance with time at $0.3 \mathrm{mg} \mathrm{mL}^{-1} \mathrm{HA}$ (b) and at $1 \mathrm{mg} \mathrm{mL}^{-1}$ (c). Latter fits correspond to a simple exponential increase. The recovered samples were diluted 1.5 times for (b) and 4 times for (c). Other conditions: see experimental section ("Neocuproine spectrophotometric assay")
The overall HA degradation by BTH in the absence and in the presence of PEG at $10 \%$ and $17 \%$ was evaluated in parallel with the neocuproine assay (Fig. 3a). It appears that the total number of reducing ends increases up to $\sim 0.3 \mathrm{mg} \mathrm{mL}^{-1}$ of HA with a little influence by PEG, in agreement with the concentration evolution of short oligomers evaluated by CE-UV. However, for higher HA concentration, the total amount of oligomers is much lower in the presence of PEG, which suggests the effective inhibition of the enzyme. The apparent $v_{\max }$ fitted according to the Michaelis-Menten kinetics decreases in the presence of 10\% PEG (dotted lines in Fig. 3a), while the decrease is moderate at $17 \%$ PEG.

\section{The speciation of HA oligomers with the time course}

HA degradation by the BTH activity was investigated, at $37{ }^{\circ} \mathrm{C}$, over a long incubation time at two fixed substrate concentrations of $0.3 \mathrm{mg} \mathrm{mL}^{-1}$ and $1 \mathrm{mg} \mathrm{mL}^{-1}$, respectively, which represents one low and one high substrate concentrations according to different reaction modes discussed above. Again, the experiments were carried out in the media without
PEG and at two concentrations of PEG (10\% and 17\%). The electrophoretic separation allows to plot the CPA of each oligomer vs. incubation time. Results are presented in Fig. 4 for [HA] at $0.3 \mathrm{mg} \mathrm{mL}^{-1}$ and in Electronic Supplementary Material (ESM) Fig. S1 for [HA] at $1 \mathrm{mg} \mathrm{mL}^{-1}$.

The speciation diagrams at $0.3 \mathrm{mg} \mathrm{mL}^{-1}$ (Fig. $4 \mathrm{a}-\mathrm{c}$ ) show a rapid and successive disappearance of oligomeric species. After $\sim 15 \mathrm{~min}$, the mixture contains only short separated oligomers (up to $\sim 20-30$ monomeric units) depending on the PEG concentration. These species reach their maximum level at some point and start to be hydrolyzed relatively rapidly. At short oligomer length, HA fragments become worst substrates for the BTH enzyme and their degradation is slower [28]. The HA degradation is additionally slowed down in solutions with PEG and this effect is more pronounced at $10 \%$ PEG compared with $17 \%$ PEG. After $\sim 60-100$ min of incubation, the CE separation of all three mixtures shows only five detectable low molecular weight oligomers (Dim, Tet, Hex, Oct, and Dec). While Oct and Dec decay relatively rapidly, the Hex species accumulates and then degrades slowly into the final products Tet and, to a lesser extent, Dim. When the effect of 


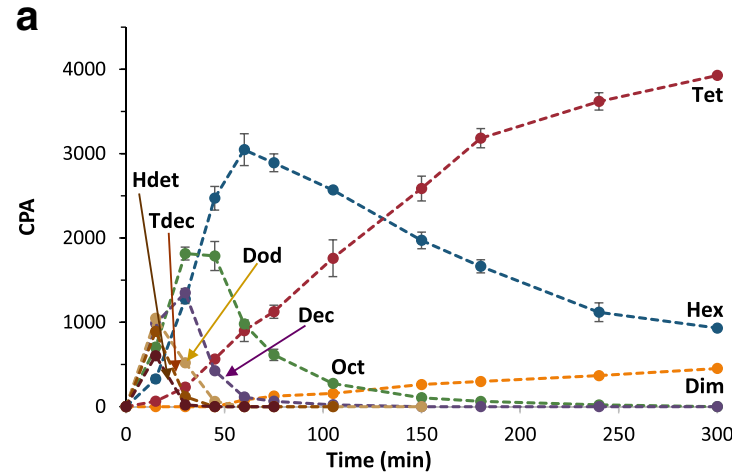

C

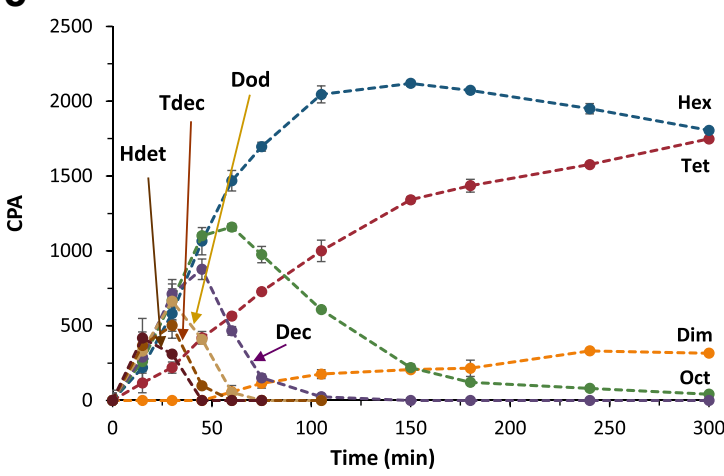

Fig. 4 Evolution of oligosaccharide species resulting from HA degradation $\left([\mathrm{HA}]=0.3 \mathrm{mg} \mathrm{mL}^{-1}\right)$ at different PEG concentrations: $0 \%$ (a); $10 \%$ (b); $17 \%$ (c). Relative molar concentration $\mathrm{C}$ of low molecular

PEG on the evolution of Tet is followed by checking the linearity zone (Fig. 5), it can be seen that the initial slope is reduced by a factor of 5 in the presence of $10 \%$ PEG and only by a factor of 2 in the presence of $17 \%$ PEG. Moreover, the formation of Tet product proceeds at a rate which is linear with time for $200 \mathrm{~min}$ in the absence of PEG $\left(r^{2}=0.9992\right)$. In the presence of $10 \%$ PEG, the linearity zone is larger by a factor of 1.5 (300 $\left.\mathrm{min}, r^{2}=0.9971\right)$, while in the highly crowded media (17\% PEG), the linearity is reduced to only $150 \mathrm{~min}$. This is probably due to the high viscosity of the media, the interaction

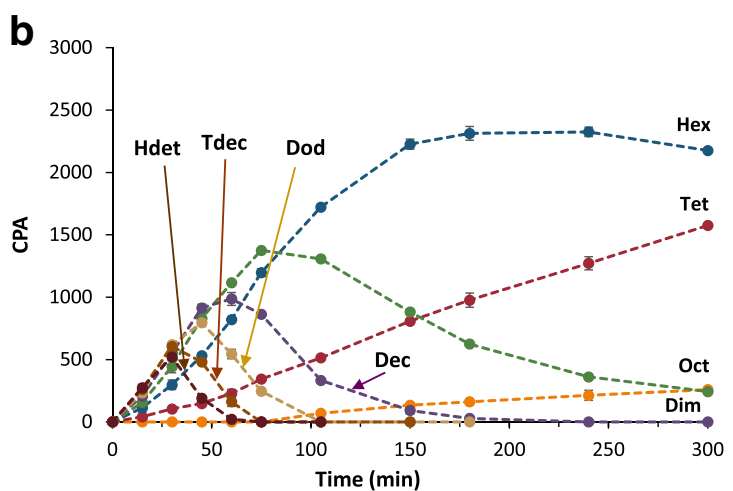

d

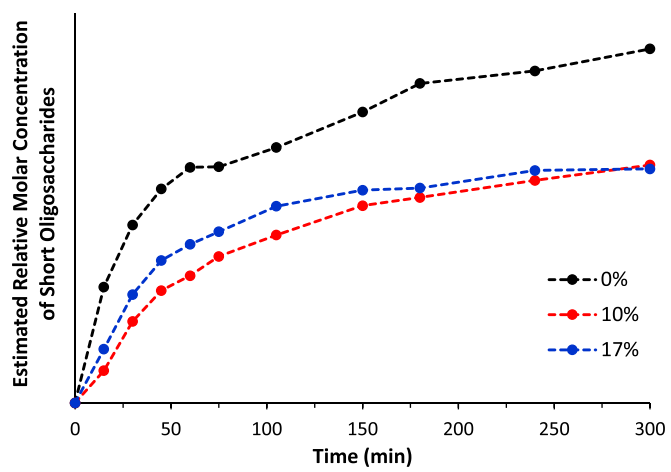

weight oligomers $\left(n=2,4,6,8\right.$, and $\left.10 ; \mathrm{C}=\sum \mathrm{c} n\right)$ with time $(\mathbf{d})$, as estimated from their individual CPA (for CE conditions, see Fig. 1). The dashed lines in the figures sare guide for the eye

between PEG and the HA, as well as the increase of the local enzymatic concentration [51].

Similar speciation studies have been performed at a high HA concentration $\left(1 \mathrm{mg} \mathrm{mL}^{-1}\right)$ (ESM Fig. S1). The reaction mixtures were continuously followed for $7 \mathrm{~h}$. The control analyses were done after 23 and $24 \mathrm{~h}$ after mixing. In this case, the peak distribution and the quantity of species for $17 \%$ PEG are rather close to those for $10 \%$ PEG and clearly different in comparison with the reaction without PEG. The evolution of oligomeric species $\left(\mathrm{CPA} \sim\right.$ mass concentration $\mathrm{mg} \mathrm{mL}^{-1}$ ) with
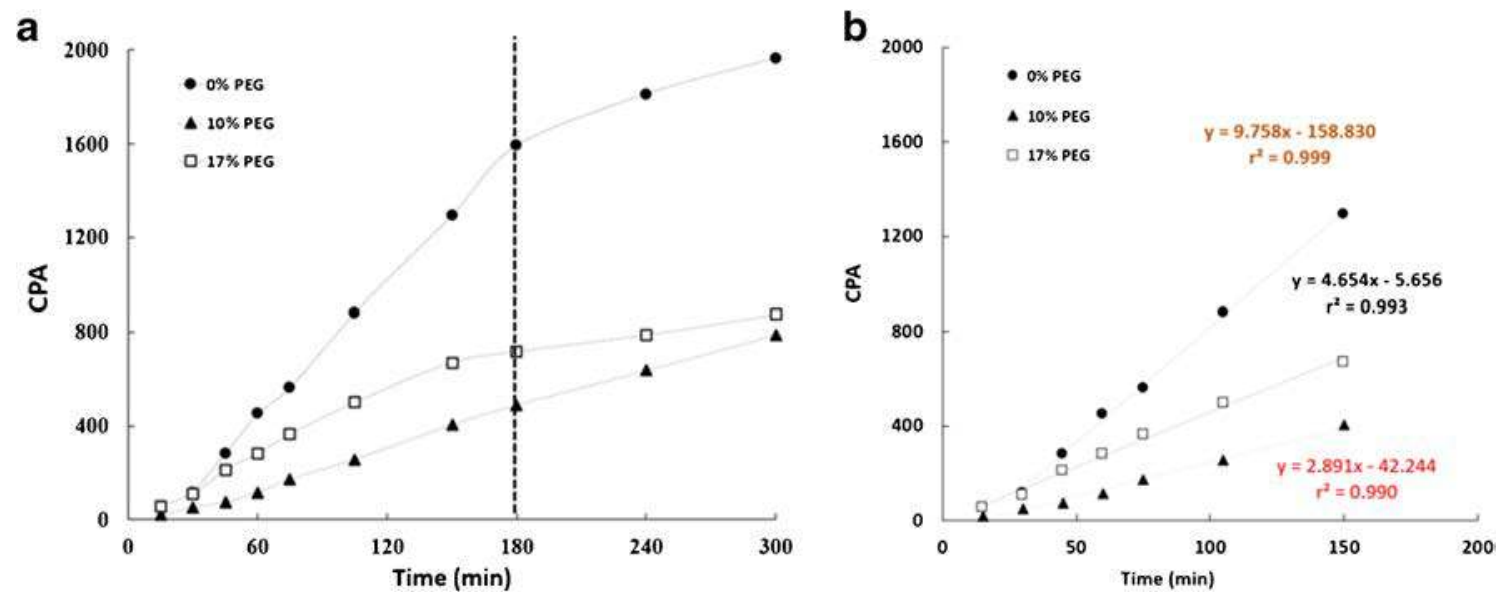

Fig. 5 CPA values of tetrasaccharide obtained by $\mathrm{CE}$ at a range of incubation time (15 to $300 \mathrm{~min})$ (a) and the linear portion of the reaction (15-150 min) (b). HA concentration: $0.3 \mathrm{mg} \mathrm{mL}^{-1}$. Other conditions: Fig. 1 


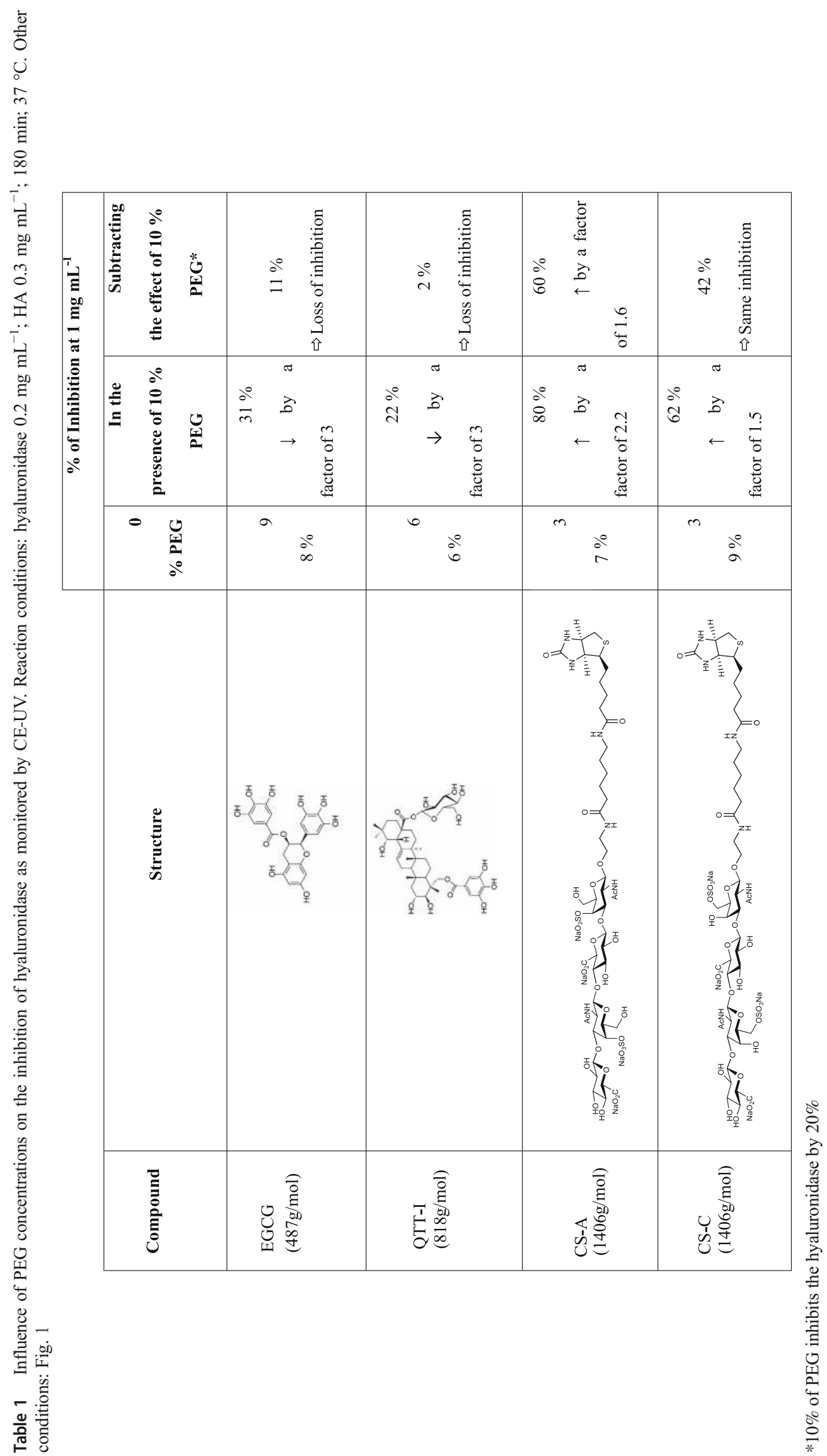


incubation time is shown in ESM Fig. S1 for three PEG concentrations. The reactions at $[\mathrm{HA}]=1 \mathrm{mg} \mathrm{mL}^{-1}$ show a similar degradation scheme to that of $[\mathrm{HA}]=0.3 \mathrm{mg} \mathrm{mL}^{-1}$ although the species evolve over a much longer duration. This effect could be correlated to a lower free concentration of BTH available for the reaction [48]. Concerning the effect of PEG, the obtained speciation data are similar and in agreement with the observations made for $[\mathrm{HA}]=0.3 \mathrm{mg} \mathrm{mL}^{-1}$, where both PEG solutions inhibit the reaction, with $10 \%$ PEG having a stronger effect. The evolution of the total molar concentrations of shorter oligosaccharides determined with $\mathrm{CE}$ is represented in Fig. 4d and ESM Fig. S1 d, respectively. The emergence of these species in PEG-containing solutions is clearly delayed and globally much slower with respect to uncrowded conditions.

The determination of the total amount of reducing ends with the neocuproine assay shows the expected exponential increase with time (Fig. 3b, c). For the reactions with $0.3 \mathrm{mg} \mathrm{mL}^{-1}$, the kinetic curves at all conditions $(0 \%$ PEG, $10 \%$ PEG, and 17\% PEG) have similar shapes. The hydrolysis is faster in the absence of PEG and the fitted global rates are $0.028 \mathrm{~min}^{-1}, 0.022 \mathrm{~min}^{-1}$, and $0.026 \mathrm{~min}^{-1}$ for 0,10 , and $17 \%$ PEG, respectively. Because of some uncertainty concerning the last point (ESM Fig. S1), the kinetic curves at $1 \mathrm{mg} \mathrm{mL}^{-1}$ HA were satisfactorily fitted up to $420 \mathrm{~min}$ to give the rates $0.0098 \mathrm{~min}^{-1}, 0.0056 \mathrm{~min}^{-1}$, and $0.0060 \mathrm{~min}^{-1} \mathrm{~s}^{-1}$ for 0,10 , and $17 \% \mathrm{PEG}$, respectively. These reaction rates are about 3-5 times lower compared with $[\mathrm{HA}]=0.3 \mathrm{mg} \mathrm{mL}^{-1}$. This difference is tentatively attributed to the inhibition effect at a high substrate concentration combined with the effect of crowding that slows down the release of hydrolysis products and simultaneously favors species recombination.

\section{Influence of PEG concentrations on the inhibition of hyaluronidase}

Four inhibitors of hyaluronidase were evaluated in the presence of $10 \%$ PEG in order to simulate a complex cellular/ extracellular matrix. The first tested inhibitor was the EGCG since it is a well-known natural reference inhibitor of hyaluronidase $\left(\mathrm{IC}_{50}=0.03 \mathrm{mg} \mathrm{mL} \mathrm{m}^{-1}\right)$ [37]. Secondly, an original natural molecule extracted from oak wood used for wine aging [42] was also tested for the first time. Finally, we tested two original synthesized inhibitors (see Experimental section), 4- and 6-biotinylated chondroitin tetrasaccharides (CS-A and CS-C), previously revealed to be efficient inhibitors of hyaluronidase by our laboratory: $\mathrm{IC}_{50}=1.46$ and $2.1 \mathrm{mg} \mathrm{mL}^{-1}$, respectively [40]. For comparison, all four inhibitors were tested at the same concentration of $1 \mathrm{mg} \mathrm{mL}^{-1}$ in the reaction mixture. The obtained results are summarized in Table 1 and show that the referenced inhibitor, EGCG, lost $69 \%$ of its inhibition effect when 10\% PEG was added to the reaction media. If the effect of the presence of PEG is subtracted from the total inhibition - which is around $20 \%$ of inhibition - the inhibition of hyaluronidase by EGCG in the presence of $10 \%$ PEG would be around $11 \%$. In other terms, the inhibition effect of EGCG is almost insignificant in a crowded medium. The same result was observed with the purified natural compound, QTT-I. This compound has been identified as a natural sweetener in wine. However, its biological effect has not been assessed yet. In this study, this compound was identified for the first time as a relevant inhibitor of the hyaluronidase in the absence of PEG. However, it lost $60 \%$ of its effect in the presence of $10 \%$ PEG, which corresponds to a null inhibition if the effect of PEG on hyaluronidase activity is subtracted. Remarkably, inhibition of CS-A and CS-C was increased in the presence of $10 \%$ PEG by a factor of 2.2 and 1.5 , respectively. This increase may be correlated to the results obtained in our previous study where CS-A had higher inhibition $\left(\mathrm{IC}_{50}=1.46 \mathrm{mg} \mathrm{mL}^{-1}\right)$ than $\mathrm{CS}-\mathrm{C}\left(\mathrm{IC}_{50}=2.21 \mathrm{mg} \mathrm{mL}^{-1}\right)$. Nevertheless, if we subtract the contribution of PEG, CS-A inhibition was slightly increased whereas the effect of CS-C remained constant (Table 1).

The effect of PEG 6000 on hyaluronidase inhibitors is most likely due to its interaction with the tested inhibitors. On the one hand, EGCG and QTT-1 have comparable neutral polycyclic structures that probably interact significantly with PEG and lead to the loss of their inhibition potential. On the other hand, the larger and negatively charged molecules CS-A and CS-C (1406 $\left.\mathrm{g} \mathrm{mol}^{-1}\right)$ have a linear scaffold probably involving weak interactions with PEG, which does not affect (or only slightly) their inhibition potential. Such linear inhibitors will bind to the BTH active sites, partially hindered by PEG or HA, more efficiently than EGCG.

\section{Conclusions}

For the first time, the activity of hyaluronidase was assessed in vitro under crowding conditions using conventional neocuproine spectrophotometry and high-performance capillary electrophoresis. The first technique allows one to determine the overall quantity of oligomeric species and requires no specific optimizations. CE on the other hand has demonstrated to be a powerful technique to follow hyaluronidase activity under different experimental conditions after appropriate optimizations. CE provided an accurate and quantitative detection of the individual products of HA degradation, which warrants a more detailed survey of the hyaluronidase activity.

The kinetic studies show that the initial fast hydrolysis of HA of relatively high molecular weight substrates is followed by slower reactions involving shorter-length substrate chains, in agreement with previous observations [52]. The CE separation of oligomers containing up to 16 monomers clearly evidences a sequential degradation of low molecular weight substrates in agreement with the fact that the stability of the 
active BTH-substrate complex decreases with the substrate length [28]. The speciation at the late stage of hydrolysis is reminiscent to the observations made by other authors for the degradation of short oligomers (Dec, Oct, Hex, and Tet) as starting substrates $[47,52,53]$. Indeed, the tetramers and dimers are accumulated as the final products of the hexamer slow cleavage, since Hex acts as the shortest but the worst substrate of the BTH.

The activity of BTH depends on the PEG concentration in the reaction media. Indeed, the presence of PEG crowding clearly results in slowing down of the global kinetics compared with standard diluted conditions. This is attributed to a combination of two inhibiting contributions as supported by our recent work [9]: (i) a non-specific interaction of PEG with the BTH-substrate complex and (ii) hindrance of product release from the BTH binding sites during the substrate cleavage and pushing toward the species recombination. Consequently, the reverse reaction, i.e., transglycosylation, is favored in the presence of PEG, and even more for short-length substrates [28]. It turns out that the overall degradation rate decreases, especially for the rate-limiting cleavage of Hex. It is evident that the presence of PEG definitively influences the subtle balance between hydrolysis and transglycosylation, both catalyzed by BTH. A stronger inhibition systematically occurs for $10 \%$ PEG comparing with $17 \%$, but it was not possible to trace back the origin of this difference from our data. In addition, at high HA concentrations, the BTH activity is reduced by the substrate inhibition, which decreases the molar fraction of the free enzyme available for the catalysis [48]. This is compatible with much slower kinetics at $1 \mathrm{mg} \mathrm{mL}^{-1}$ of HA, where the degradation mechanism remains similar to that observed at lower HA concentrations.

More interestingly, the inhibition of hyaluronidase by natural and synthetized compounds is affected by the presence of crowders, depending on the inhibitors' structure and their ability to interact with PEG. EGCG and QTT-1, both of which are neutral and relatively small and compact molecules, lost their influence on hyaluronidase in the presence of $10 \%$ PEG. The original synthesized inhibitors, CS-A and CS-C, which are charged linear compounds were affected differently and did not lose their inhibition potential. This promotes these compounds to be used as potential in vivo inhibitors of hyaluronidase.

Accordingly, our results confirm the importance of designing novel assays that would include mimicking the cellular environment for the development of new therapeutic drugs or cosmetic products screening. The effect of crowded media on enzyme activity is difficult to predict in a systematical manner, but crowding should be definitively included among the key factors to be considered for the development of reliable inhibitors of hyaluronidase. With the speciation data in hand, we intend to develop, in the near future, a global kinetic model for better understanding of the relevant molecular reaction mechanism.

Funding information This work has been financially supported by the University of Orléans (France), the CNRS (Centre National de la Recherche Scientifique, France), and the Labex SynOrg (ANR-11LABX-0029).

\section{Compliance with ethical standards}

Conflict of interest The authors declare that they have no conflict of interest.

\section{References}

1. van den Berg B, Ellis RJ, Dobson CM. Effects of macromolecular crowding on protein folding and aggregation. EMBO J. 1999;18: 6927-33. https://doi.org/10.1093/emboj/18.24.6927.

2. Ellis RJ, Minton AP. Protein aggregation in crowded environments. Biol Chem. 2006;387:485-97. https://doi.org/10.1515/BC.2006. 064.

3. Ellis RJ. Macromolecular crowding: an important but neglected aspect of the intracellular environment. Curr Opin Struct Biol. 2001;11:114-9. https://doi.org/10.1016/s0959-440x(00)00172-x.

4. Das N, Sen P. Size-dependent macromolecular crowding effect on the thermodynamics of protein unfolding revealed at the single molecular level. Int J Biol Macromol. 2019;141:843-54. https:// doi.org/10.1016/j.ijbiomac.2019.09.029.

5. Kuznetsova IM, Turoverov KK, Uversky VN. What macromolecular crowding can do to a protein. Int J Mol Sci. 2014;15:23090140. https://doi.org/10.3390/ijms151223090.

6. Anderegg U, Simon JC, Averbeck M. More than just a filler - the role of hyaluronan for skin homeostasis. Exp Dermatol. 2014;23: 295-303. https://doi.org/10.1111/exd.12370.

7. Bhakuni K, Venkatesu P. Crowded milieu tuning the stability and activity of stem bromelain. Int J Biol Macromol. 2018;109:114-23. https://doi.org/10.1016/j.ijbiomac.2017.12.060.

8. Nolan V, Clop PD, Burgos MI, Perillo MA. Dual substrate/solventroles of water and mixed reaction-diffusion control of $\beta$ galactosidase catalyzed reactions in PEG-induced macromolecular crowding conditions. Biochem Biophys Res Commun. 2019;515: 190-5. https://doi.org/10.1016/j.bbrc.2019.05.081.

9. Matić M, Saurabh S, Hamacek J, Piazza F. Crowding-induced uncompetitive inhibition of lactate dehydrogenase: role of entropic pushing. J Phys Chem B. 2020;124:727-34. https://doi.org/10. 1021/acs.jpcb.9b09596.

10. Olsen SN, Ramløv H, Westh P. Effects of osmolytes on hexokinase kinetics combined with macromolecular crowding: test of the osmolyte compatibility hypothesis towards crowded systems. Comp Biochem Physiol, Part A Mol Integr Physiol. 2007;148: 339-45. https://doi.org/10.1016/j.cbpa.2007.05.009.

11. Shahid S, Ahmad F, Hassan MI, Islam A. Relationship between protein stability and functional activity in the presence of macromolecular crowding agents alone and in mixture: an insight into stability-activity trade-off. Arch Biochem Biophys. 2015;584:4250. https://doi.org/10.1016/j.abb.2015.08.015.

12. Sastre Toraño J, Ramautar R, de Jong G. Advances in capillary electrophoresis for the life sciences. J Chromatogr B. 2019;11181119:116-36. https://doi.org/10.1016/j.jchromb.2019.04.020.

13. Nehmé H, Nehmé R, Lafite P, Routier S, Morin P. New development in in-capillary electrophoresis techniques for kinetic and 
inhibition study of enzymes. Anal Chim Acta. 2012;722:127-35. https://doi.org/10.1016/j.aca.2012.02.003.

14. Hai X, Wang X, El-Attug M, Adams E, Hoogmartens J, Van Schepdael A. In-capillary screening of matrix metalloproteinase inhibitors by electrophoretically mediated microanalysis with fluorescence detection. Anal Chem. 2011;83:425-30. https://doi.org/ 10.1021/ac1027098.

15. Řemínek R, Zeisbergerová M, Langmajerová M, Glatz Z. New capillary electrophoretic method for on-line screenings of drug metabolism mediated by cytochrome P450 enzymes. Electrophoresis. 2013;34:2705-11. https://doi.org/10.1002/elps.201300124.

16. Langmajerová M, Remínek R, Pelcová M, Foret F, Glatz Z. Combination of on-line CE assay with MS detection for the study of drug metabolism by cytochromes P450. Electrophoresis. 2015;36:1365-73. https://doi.org/10.1002/elps.201400394.

17. Fayad S, Nehmé R, Langmajerová M, Ayela B, Colas C, Maunit B, et al. Hyaluronidase reaction kinetics evaluated by capillary electrophoresis with UV and high-resolution mass spectrometry (HRMS) detection. Anal Chim Acta. 2017;951:140-50. https:// doi.org/10.1016/j.aca.2016.11.036.

18. Nehmé R, Atieh C, Fayad S, Claude B, Chartier A, Tannoury M, et al. Microalgae amino acid extraction and analysis at nanomolar level using electroporation and capillary electrophoresis with laserinduced fluorescence detection. J Sep Sci. 2017;40:558-66. https:// doi.org/10.1002/jssc.201601005.

19. Zhou W, Zhang B, Liu Y, Wang C, Sun W, Li W, et al. Advances in capillary electrophoresis-mass spectrometry for cell analysis. TrAC Trends in AnalChem. 2019;117:316-30. https://doi.org/10.1016/j. trac.2019.05.011.

20. Claude B, Cutolo G, Farhat A, Zarafu I, Ionita P, Schuler M, et al. Capillary electrophoresis with dual detection UV/C4D for monitoring myrosinase-mediated hydrolysis of thiol glucosinolate designed for gold nanoparticle conjugation. Anal Chim Acta. 2019;1085: 117-25. https://doi.org/10.1016/j.aca.2019.07.043.

21. Fan Y, Scriba GKE. Advances in-capillary electrophoretic enzyme assays. J Pharmaceut Biomed. 2010;53:1076-90. https://doi.org/ 10.1016/j.jpba.2010.04.005

22. Vercruysse KP, Lauwers AR, Demeester JM. Kinetic investigation of the action of hyaluronidase on hyaluronan using the MorganElson and neocuproine assays. Biochem J. 1995;310:55-9. https://doi.org/10.1042/bj3100055.

23. Bukhari SNA, Roswandi NL, Waqas M, Habib H, Hussain F, Khan $\mathrm{S}$, et al. Hyaluronic acid, a promising skin rejuvenating biomedicine: a review of recent updates and pre-clinical and clinical investigations on cosmetic and nutricosmetic effects. Int J Biol Macromol. 2018;120:1682-95. https://doi.org/10.1016/j.ijbiomac. 2018.09.188

24. Cowman MK. Chapter One - Hyaluronan and hyaluronan fragments. Adv Carbohydr Chem Biochem. 2017;74:1-59. https://doi. org/10.1016/bs.accb.2017.10.001

25. Lee DH, Oh J-H, Chung JH. Glycosaminoglycan and proteoglycan in skin aging. J Dermatol Sci. 2016;83:174-81. https://doi.org/10. 1016/j.jdermsci.2016.05.016.

26. Maquart FX, Monboisse JC. Extracellular matrix and wound healing. Pathol Biol. 2014;62:91-5. https://doi.org/10.1016/j. patbio.2014.02.007.

27. Theocharis AD, Skandalis SS, Gialeli C, Karamanos NK. Extracellular matrix structure. Adv Drug Deliv Rev. 2016;97:4 27. https://doi.org/10.1016/j.addr.2015.11.001.

28. Lee A, Grummer S, Kriegel D, Marmur E. Hyaluronidase. Dermatol Surg. 2010;36:1071-7. https://doi.org/10.1111/j.15244725.2010.01585.x.

29. Deschrevel B, Tranchepain F, Vincent J-C. Chain-length dependence of the kinetics of the hyaluronan hydrolysis catalyzed by bovine testicular hyaluronidase. Matrix Biol. 2008;27:475-86. https://doi.org/10.1016/j.matbio.2008.01.007.
30. Novak U, Stylli SS, Kaye AH, Lepperdinger G. Hyaluronidase-2 overexpression accelerates intracerebral but not subcutaneous tumor formation of murine astrocytoma cells. Cancer Res. 1999;59: 6246-50.

31. Stern R. Hyaluronidases in cancer biology. Semin Cancer Biol. 2008;18:275-80. https://doi.org/10.1016/j.semcancer.2008.03.017.

32. Vercruysse KP, Lauwers AR, Demeester JM. Absolute and empirical determination of the enzymatic activity and kinetic investigation of the action of hyaluronidase on hyaluronan using viscosimetry. Biochem J. 1995;306(Pt 1):153-60. https://doi.org/ 10.1042/bj3060153.

33. Fang S, Hays Putnam A-MA, LaBarre MJ. Kinetic investigation of recombinant human hyaluronidase $\mathrm{PH} 20$ on hyaluronic acid. Anal Biochem. 2015;480:74-81. https://doi.org/10.1016/j.ab.2015.04. 008 .

34. Tao L, Song F, Xu N, Li D, Linhardt RJ, Zhang Z. New insights into the action of bacterial chondroitinase AC I and hyaluronidase on hyaluronic acid. Carbohydr Polym. 2017;158:85-92. https://doi. org/10.1016/j.carbpol.2016.12.010.

35. Addotey JN, Lengers I, Jose J, Hensel A. Hyal-1 inhibitors from the leaves of Phyllanthus muellerianus (Kuntze) Excell. J Ethnopharmacol. 2019;236:326-35. https://doi.org/10.1016/j.jep. 2019.03.022.

36. La Gatta A, De Rosa M, Marzaioli I, Busico T, Schiraldi C. A complete hyaluronan hydrodynamic characterization using a size exclusion chromatography-triple detector array system during in vitro enzymatic degradation. Anal Biochem. 2010;404:21-9. https://doi.org/10.1016/j.ab.2010.04.014.

37. Fayad S, Morin P, Nehmé R. Use of chromatographic and electrophoretic tools for assaying elastase, collagenase, hyaluronidase, and tyrosinase activity. J Chromatogr A. 2017;1529:1-28. https://doi. org/10.1016/j.chroma.2017.11.003.

38. Grimshaw J. Analysis of glycosaminoglycans and their oligosaccharide fragments by capillary electrophoresis. Electrophoresis. 1997;18:2408-14. https://doi.org/10.1002/elps.1150181231.

39. Grundmann M, Rothenhöfer M, Bernhardt G, Buschauer A, Matysik F-M. Fast counter-electroosmotic capillary electrophoresis-time-of-flight mass spectrometry of hyaluronan oligosaccharides. Anal Bioanal Chem. 2012;402:2617-23. https:// doi.org/10.1007/s00216-011-5254-2.

40. Fayad S, Ayela B, Chat C, Morin P, Lopin-Bon C, Nehmé R. Effect of modified di- and trisaccharides on hyaluronidase activity assessed by capillary electrophoresis-based enzymatic assay. Carbohydr Res. 2019;475:56-64. https://doi.org/10.1016/j.carres. 2019.02.006.

41. Ait-Mohand K, Lopin-Bon C, Jacquinet J-C. Synthesis of variously sulfated biotinylated oligosaccharides from the linkage region of proteoglycans. Carbohydr Res. 2012;353:33-48. https://doi.org/ 10.1016/j.carres.2012.03.039.

42. Marchal A, Waffo-Téguo P, Génin E, Mérillon J-M, Dubourdieu D. Identification of new natural sweet compounds in wine using centrifugal partition chromatography-gustatometry and Fourier transform mass spectrometry. Anal Chem. 2011;83:9629-37. https://doi. org/10.1021/ac202499a.

43. Stern R, Jedrzejas MJ. Hyaluronidases: their genomics, structures, and mechanisms of action. Chem Rev. 2006;106:818-39. https:// doi.org/10.1021/cr050247k.

44. Nehmé R, Perrin C, Cottet H, Blanchin M-D, Fabre H. Influence of polyelectrolyte capillary coating conditions on protein analysis in CE. Electrophoresis. 2009;30:1888-98. https://doi.org/10.1002/ elps.200800688.

45. Mittal S, Chowhan RK, Singh LR. Macromolecular crowding: macromolecules friend or foe. Biochim Biophys Acta. 2015;1850: 1822-31. https://doi.org/10.1016/j.bbagen.2015.05.002.

46. Nehmé R, Perrin C, Cottet H, Blanchin MD, Fabre H. Influence of polyelectrolyte coating conditions on capillary coating stability and 
separation efficiency in capillary electrophoresis. Electrophoresis. 2008;29:3013-23. https://doi.org/10.1002/elps.200700886.

47. Horvath J, Dolník V. Polymer wall coatings for capillary electrophoresis. Electrophoresis. 2001;22:644-55. https://doi.org/10. 1002/1522-2683(200102)22:4<644::AID-ELPS644>3.0.CO;2-3.

48. Lenormand H, Amar-Bacoup F, Vincent J-C. Reactioncomplexation coupling between an enzyme and its polyelectrolytic substrate: determination of the dissociation constant of the hyaluronidase-hyaluronan complex from the hyaluronidase substrate-dependence. Biophys Chem. 2013;175-176:63-70. https:// doi.org/10.1016/j.bpc.2013.02.007.

49. Dong Q, Guo X, Li L, Yu C, Nie L, Tian W, et al. Understanding hyaluronic acid induced variation of water structure by nearinfrared spectroscopy. Sci Rep. 2020;10:1-8. https://doi.org/10. 1038/s41598-020-58417-5.

50. Han J, Herzfeld J. Macromolecular diffusion in crowded solutions. Biophys J. 1993;65:1155-61. https://doi.org/10.1016/S00063495(93)81145-7.
51. Zimmerman SB, Trach SO. Estimation of macromolecule concentrations and excluded volume effects for the cytoplasm of Escherichia coli. J Mol Biol. 1991;222:599-620. https://doi.org/ 10.1016/0022-2836(91)90499-v.

52. Kakizaki I, Ibori N, Kojima K, Yamaguchi M, Endo M. Mechanism for the hydrolysis of hyaluronan oligosaccharides by bovine testicular hyaluronidase. FEBS J. 2010;277:1776-86. https://doi.org/10. 1111/j.1742-4658.2010.07600.x.

53. Hofinger ESA, Bernhardt G, Buschauer A. Kinetics of Hyal-1 and PH-20 hyaluronidases: comparison of minimal substrates and analysis of the transglycosylation reaction. Glycobiology. 2007;17: 963-71. https://doi.org/10.1093/glycob/cwm070. 